\title{
REMOVAL OF REACTIVE RED 120 IN AQUEOUS SOLUTION USING Mg-HYDROTALCITES AS ADSORBENTS SOLIDS: KINETICS AND ISOTHERMS
}

Remoción de rojo reactivo 120 en solución acuosa usando hidrotalcitas de Mg como sólidos adsorbentes: cinética e isotermas

\author{
Ivone JURADO DÁVILA*, Morgana ROSSET, Oscar PEREZ LOPEZ and Liliana AMARAL FÉRIS
}

Federal University of Rio Grande do Sul, Department of Chemical Engineering, Ramiro Barcelos Street, 2777 , CP 90035-007 Porto Alegre - RS, Brazil

*Corresponding author: vanessa@enq.ufrgs.br

(Received: February 2019; accepted: August 2019)

Key words: adsorption, dye, water, materials

\begin{abstract}
Reactive red 120 (RR120) is a widely used dye in the textile industry but its release in aqueous wastewater is a serious problem due to its toxicity and low biodegradability. The aim of this work was to evaluate the effect of the trivalent cation of magnesiumbased materials type hydrotalcite as adsorbents applied to RR120 dye removal in aqueous solution. The samples were synthesized by continuous coprecipitation and were characterized by surface area measurements, X-ray diffraction and temperatureprogrammed desorption of $\mathrm{CO}_{2}$. Dye adsorption tests were carried out using different adsorbent dosages and contact time. The kinetic adsorption was studied for the pseudofirst and pseudo-second order models. The equilibrium adsorption data were fitted to the Langmuir, Freundlich and Redlich-Peterson isotherm models. The most suitable adsorption conditions were found at a residence time of $60 \mathrm{~min}$ and solid dosage of $2.5 \mathrm{~g} / \mathrm{L}$ for HDL-MgFe, $2 \mathrm{~g} / \mathrm{L}$ for HDL-MgAl and HC-Mg. The results showed that pseudo-second order model, as well as the Langmuir and Redlich-Peterson models best described the removal process. The Al containing compound presented the best results due to a better interaction between strength and number of basic sites.
\end{abstract}

Palabras clave: adsorción, colorante, agua, materiales

\section{RESUMEN}

El rojo reactivo 120 es un colorante ampliamente utilizado en la industria textil, pero su liberación en aguas residuales es un problema grave debido a su toxicidad y baja biodegradabilidad. El objetivo de este trabajo fue evaluar el efecto del catión trivalente de materiales tipo hidrotalcita a base de magnesio como sólidos adsorbentes aplicados a la eliminación del colorante rojo reactivo 120 en solución acuosa. Las muestras se sintetizaron mediante coprecipitación continua y se caracterizaron por medidas de área superficial, difracción de rayos $\mathrm{X}$ y desadsorción de $\mathrm{CO}_{2}$ programada por temperatura. Las pruebas de adsorción de colorantes se llevaron a cabo utilizando diferentes concentraciones de adsorbente y tiempo de contacto. La cinética de adsorción se estudió para los modelos de seudoprimer y seudosegundo orden. Los datos de adsorción de equilibrio se ajustaron a los modelos de isotermas de Langmuir, Freundlich y RedlichPeterson. Las condiciones de adsorción más adecuadas se encontraron en un tiempo de 
residencia de 60 min y una concentración del sólido de $2.5 \mathrm{~g} / \mathrm{L}$ para HDL-MgFe, y $2 \mathrm{~g} / \mathrm{L}$ para HDL-MgAl y HC-Mg. Los resultados mostraron que el modelo de seudosegundo orden y de Langmuir y Redlich-Peterson describían mejor el proceso de eliminación del colorante. Además, el compuesto que contienía Al presentó los mejores resultados debido a una mejor interacción entre la fuerza y el número de sitios básicos.

\section{INTRODUCTION}

Effluents from industrial sources are a major cause of environmental pollution. Technological advances have led to an increase in water pollution with a variety of materials, both in features and in the degree of ecological risk, which means serious environmental impact that needs new efficient and economical methods for disposal. According to Lemlikchi et al. (2015), effluents from textile industries have a higher potential for contamination and health risks. Therefore, they need a pretreatment before being discarded into the environment.

Industrial effluents that include dyes generate a highly toxic effect on aquatic organisms. Besides that, synthetic dyes have a high degree of aromaticity and low biodegradability (Uddin et al. 2009). From the environmental point of view, dye removal from wastewater is one of the main problems faced by the textile sector. The high biological stability of dyes makes their degradation difficult by the conventional treatment systems used by the textile industries (Huang et al. 2017).

Moreover, textile dyes have a high degree of aromaticity and low biodegradability (Uddin et al. 2009). Anionic synthetic dyes such as RR120, can be degraded to aromatic amines, which are carcinogenic under anaerobic conditions (Senthilkumaar et al. 2006), Therefore, alternative ways to remove this molecule should be used.

The removal of RR120 from aqueous solution was previously studied by different techniques as advanced oxidation processes (Kusvuran et al. 2004) or photocatalytic degradation (Cho and Zoh 2007). Taking into account the economic aspects, the use of advanced oxidation processes and photocatalytic degradation is not advisable due to high operating and capital costs, although they represent efficient processes for the removal of RR120. However, adsorption is a very studied technique in different systems of removal due to its efficiency and low cost (Crini 2006, Punjongharn et al. 2008, Çelekli et al. 2009, Franco et al. 2017, Haro et al. 2017).

Among the solids studied in adsorption processes are activated carbon (Senthilkumaar et al. 2006), nanoparticles of $\mathrm{Fe}_{3} \mathrm{O}_{4}$ modified by ionic liquid ( $\mathrm{Ab}$ salan et al. 2011), biomass from green alga (Çelekli et al. 2009), or biosorbents as the Nepenthes rafflesiana pitcher or Artocarpus odoratissimus (Kooh et al. $2017 \mathrm{a}, \mathrm{b})$. Other important solids are hydrotalcites, which are used as heterogeneous catalysts and anionic exchangers in the pharmaceutical industry, and as adsorbents of pollutants in effluents (Vaccari 1998, Rives et al. 2013, Fan et al. 2014, Bharali and Deka 2017, Zubair et al. 2017).

Hydrotalcites have been of great interest for wastewater applications. Several studies have been devoted to the investigation of their ability to remove different compounds from contaminated water, in which adsorption and anion exchange have shown great potential to this aim. Shan et al. (2015) reported obtaining magnesium and aluminum hydrotalcite and evaluated its effectiveness in the removal of three red dyes by the adsorption method. The results obtained show that the dyes were adsorbed with efficiencies higher than $90 \%$. The isotherms in this study corresponded to the Langmuir model. Lazaridis et al. (2003) studied the removal of a reactive dye, cibacron yellow LS-R, on hydrotalcite particles as adsorbent solid. The isotherms were described by the Langmuir model. Guo et al. (2013) used the $\mathrm{Cu} / \mathrm{Mg} / \mathrm{Fe}$ layered double hydroxide calcined as adsorbent for the removal of acid brown 14 from an aqueous solution with isotherms that corresponded to the Langmuir model.

In this context, the objective of this work was to evaluate the removal of RR120 dye by adsorption using the trivalent cations of magnesium hydroxycarbonate $(\mathrm{HC}-\mathrm{Mg}$ ) and hydrotalcites of magnesium containing aluminum (HDLMgAl) or iron (HDLMg$\mathrm{Fe}$ ) as as solids adsorbents.

\section{MATERIALS AND METHODS}

RR120 with $99 \%$ of purity (molar weight $1469.98 \mathrm{~g} / \mathrm{mol}$, CAS-No 61951-82-4 and linear formula $\mathrm{C}_{44} \mathrm{H}_{24} \mathrm{Cl}_{2} \mathrm{~N} 14 \mathrm{Na}_{6} \mathrm{O}_{20} \mathrm{~S}_{6}$ ) was obtained from Sigma-Aldrich and was used as adsorbate without further purification. Figure 1 shows that it contains two azo groups as chromophores, two chlorotriazine 
groups as reagents, six sulfonic acid groups and two phenolic OH groups (Paul et al. 2011).

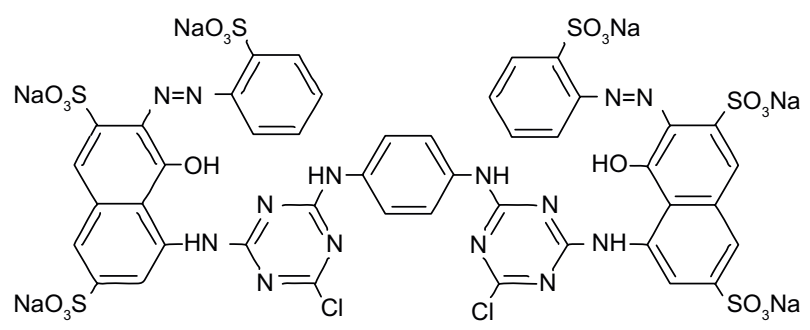

Fig. 1. Chemical structure of Reactive Red 120

\section{Synthesis of adsorbents}

The adsorbent solids were prepared by the continuous co-preparation method previously reported by Perez-Lopez et al. (2006). Two aqueous solutions were prepared: solution A containing nitrates of the metals $\mathrm{Mg}\left(\mathrm{NO}_{3}\right)_{2} .6 \mathrm{H}_{2} \mathrm{O}$ and $\mathrm{Al}\left(\mathrm{NO}_{3}\right)_{3} .9 \mathrm{H}_{2} \mathrm{O}$ for $\mathrm{HDL}-\mathrm{MgAl}$; and of $\mathrm{Mg}\left(\mathrm{NO}_{3}\right)_{2} \cdot 6 \mathrm{H}_{2} \mathrm{O}$ and $\mathrm{Fe}\left(\mathrm{NO}_{3}\right)_{3} .9 \mathrm{H}_{2} \mathrm{O}$ for HDLMgFe. Solution B was composed by a mixture of $\mathrm{NaOH}$ and $\mathrm{Na}_{2} \mathrm{CO}_{3}$. The atomic ratio between bivalent and trivalent metal cations $\left(\mathrm{M}^{2+} / \mathrm{M}^{3+}\right)$ was maintained at 3. For the synthesis of $\mathrm{HCMg}$, solutions $\mathrm{A}$ and $\mathrm{B}$ were composed of $\mathrm{Mg}\left(\mathrm{NO}_{3}\right)_{2} \cdot 6 \mathrm{H}_{2} \mathrm{O}$ and $\mathrm{Na}_{2} \mathrm{CO}_{3}$, respectively. These two solutions were mixed simultaneously in a glass continuous stirred-tank reactor (CSTR), with constant temperature and $\mathrm{pH}$. The precipitate was maintained under agitation for $1 \mathrm{~h}$ at $50^{\circ} \mathrm{C}$, and then vacuum filtered, washed with deionized water and dried in an oven at $80^{\circ} \mathrm{C}$ overnight.

\section{Characterization}

The solids were characterized by X-ray diffraction (XRD), $\mathrm{N}_{2}$ adsorption/desorption (BET) and temperature-programmed desorption (TPD- $\mathrm{CO}_{2}$ ).

The X-ray diffraction patterns were collected through the powder method with a Bruker D2-phaser diffractometer using $\mathrm{Cu}-\mathrm{K} \alpha$ radiation $(\lambda=1.5406 \AA)$ at $30 \mathrm{kV}$ and $10 \mathrm{~mA}, 2 \mathrm{q}$ between 5 and $70^{\circ}$, and step of $0.02^{\circ} \mathrm{s}^{-1}$.

The surface area measurements were performed on a NOVA 1000 e equipment (Quantachrome Instruments). Nitrogen was used as inert gas, and a pretreatment with vacuum for $1 \mathrm{~h}$ at a temperature of $300{ }^{\circ} \mathrm{C}$ was performed.

TPD- $\mathrm{CO}_{2}$ profiles were performed in a multipurpose system using $100 \mathrm{mg}$ of the sample. Initially, the samples were degassed at $100{ }^{\circ} \mathrm{C}$ with a helium flow, for $30 \mathrm{~min}$. Then, samples were saturated with $30 \mathrm{~mL} / \mathrm{min}$ of $\mathrm{CO}_{2}$. After adsorption, the samples were purged with a pure helium stream to remove species that were not adsorbed. Subsequently, the heating was initiated at $10{ }^{\circ} \mathrm{C} / \mathrm{min}$ with helium flow of $30 \mathrm{~mL} / \mathrm{min}$. The desorption curves were recorded with a thermal conductivity detector (TCD).

\section{Adsorption experiments}

The adsorption tests were performed in batch mode using volumes of $100 \mathrm{~mL}$ of RR120 solutions. In each test, the adsorbent was added to the solution and the process parameters to obtain the best experimental conditions were evaluated. All experiments were performed in duplicate. Considering that the prepared adsorbents have alkaline properties, and the dye used as a pollutant is acidic in nature so the intensity of its color is affected by sudden changes in $\mathrm{pH}$, the experiments were carried out at the natural $\mathrm{pH}$ of the solution containing the solids, which was approximately 8 .

The best experimental conditions were obtained by adsorption experiments using $100 \mathrm{~mL}$ of an RR120 solution (30 mg/L), and HDL-MgAl, HDL-MgFe and $\mathrm{HC}-\mathrm{Mg}$ as adsorbents. The effect of adsorbent dosage was investigated considering different dosages of the three solids $(0.05,0.1,0.15,0.2,0.25,0.3$ and $0.35 \mathrm{~g})$. For these tests, the adsorption contact time was $30 \mathrm{~min}$. Contact time experiments $(5,10,20,40$, 60,90 and $120 \mathrm{~min}$ ) were performed applying the best adsorbent concentration obtained. All experiments were performed in duplicate and the solutions were centrifuged in a CIENTEC equipment, model CT5000R, at $6000 \mathrm{rpm}$ for $10 \mathrm{~min}$ and analyzed in a spectrophotometer at a wavelength of $535 \mathrm{~nm}$. The amount of dye adsorbed was calculated by equation 1 .

$q t=\frac{\left(C_{0}-C_{t}\right) x V}{m}$

where $C_{0}(\mathrm{mg} / \mathrm{L})$ was the initial concentration of dye, $C_{\mathrm{t}}(\mathrm{mg} / \mathrm{L})$ was the concentration of dye at time $t, q_{\mathrm{t}}$ $(\mathrm{mg} / \mathrm{g})$ was the adsorbed amount at time $t, V(\mathrm{~L})$ was the volume of phosphate solutions, and $m(\mathrm{~g})$ was the dosage of the adsorbent solids.

\section{Isotherms and adsorption kinetics}

The kinetic data were analyzed using pseudo-first order and pseudo-second order models. Isotherms were constructed by conducting experiments varying the concentration of the dye solution $(10,20,30,40$, $50,60,70,80,90,100,200,300,400$ and $500 \mathrm{mg} / \mathrm{L}$ ). Solids dosage and adsorption time were used according to the last item. Three different isotherm models were tested to fit the equilibrium data: Langmuir, Freundlich and Redlich-Peterson. 
For the parameters estimation of each model, equation 2 was used to minimize errors:

Error $=\left(\frac{q_{e}^{\text {calcu }}-q_{e}^{\text {exp }}}{q_{e}^{\exp }}\right)^{2}$

where $q_{\mathrm{e}}^{\text {calc }}$ and $q_{\mathrm{e}}{ }^{\text {exp }}$ represent the amount adsorbed in equilibrium calculated by the models and the experimental values, respectively.

\section{RESULTS AND DISCUSSION}

It can be seen in figure 1 that RR120 has an anionic structure and it is basic in an aqueous medium. This characteristic is important for choosing the adequate solid adsorbent for the removal process. The maximum adsorption capacity is not only influenced by the surface of the adsorbent solids but also involves the dye chemistry and the acid-base properties of these solids. Therefore, characterizing the solids to know their properties, such as surface area, crystallinity or basic sites, is important to explain the adsorption of dyes with acidic characteristics.

\section{Characterization}

The XRD patterns of the adsorbents can be observed in figure 2. The diffractograms of HDL-MgAl

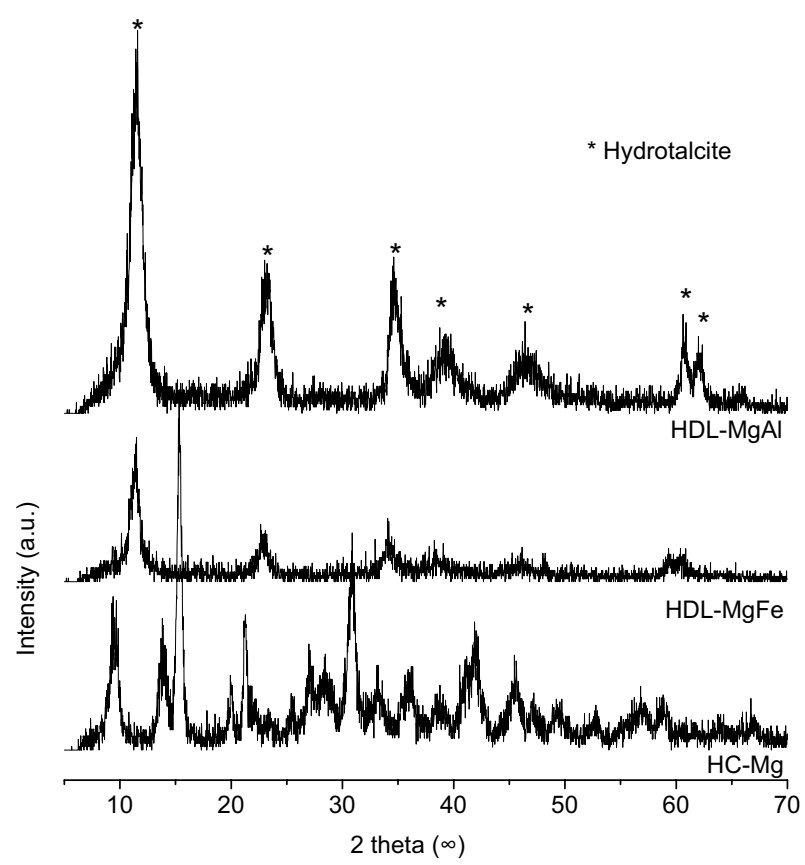

Fig. 2. X-ray diffractogram of $\mathrm{MgAl}$ and $\mathrm{MgFe}$ hydrotalcites (HDL-MgAl and HDL-MgFe, respectively), and $\mathrm{Mg}$ hydroxycarbonate (HC-Mg) and HDL-MgFe present peaks corresponding to the structure of the hydrotalcites, which show three main peaks at approximately 11,22 and $35^{\circ}$. These reflections correspond to diffraction by planes (003), (006) and (009) and represent the separations between layers (Vicente 2002). These materials present common features such as the presence of intense and sharp peaks for low angle values and less intense peaks for larger angle values that are generally asymmetric (Cavani et al. 1991).

The diffractogram for $\mathrm{HC}-\mathrm{Mg}$ shows peaks corresponding to hydromagnesite or magnesium hydroxycarbonate, similar to those reported in the literature by Beall et al. (2013). The crystallinity of the structure is evidenced by the two main reflections at approximately 15 and $30^{\circ}$.

The lamellar double hydroxides synthesized presented good crystallization and a structure between layers similar to those reported in the literature (Tsyganok and Sayari 2006, Guo et al. 2013, Shan et al. 2015). Comparing the HDL-MgAl and HDLMgFe diffractograms, the sample with $\mathrm{Al}$ forms a hydrotalcite with higher crystallinity and more intense reflections than THE sample with Fe.

Table I presents the results of the specific surface area (BET) and the number of basic sites obtained in the TPD- $\mathrm{CO}_{2}$ measurements. Hydrotalcite-type samples show high surface area values in comparison with $\mathrm{HC}-\mathrm{Mg}$. The main reason for this difference is due to the structure of lamellar double hydroxides having a large surface with spaces between layers (Vaccari 1998). The iron-containing hydrotalcite (HDL-MgFe) has a larger surface area than the aluminum-containing hydrotalcite (HDL-MgAl), which is in accordance with the lower crystallinity of HDL-MgF revealed in the XRD pattern (Fig. 2). This fact is important because the ability to solute

TABLE I. SPECIFIC SURFACE AREA AND NUMBER OF BASIC SITES

\begin{tabular}{lccc}
\hline Samples & $\begin{array}{c}\text { Surface } \\
\text { area BET } \\
\left(\mathrm{m}^{2} / \mathrm{g}\right)\end{array}$ & $\begin{array}{c}\text { Maximum } \\
\text { temperature } \\
\text { of the basic } \\
\text { peak }\left({ }^{\circ} \mathrm{C}\right)\end{array}$ & $\begin{array}{c}\text { Total number of } \\
\text { basic sites } \\
(\mathrm{mmol} / \mathrm{g})\end{array}$ \\
\hline $\begin{array}{l}\text { Hydrotalcite } \\
\text { of MgAl }\end{array}$ & 75 & 335 & 0.3 \\
\hline $\begin{array}{l}\text { Hydrotalcite } \\
\text { of MgFe }\end{array}$ & 119 & 385 & 0.2 \\
$\begin{array}{l}\text { Hydroxycarbonate } \\
\text { of Mg }\end{array}$ & 67 & 303 & 0.7 \\
\hline
\end{tabular}


removal is also related to the available surface area in the adsorbent and to the size of the adsorbate molecule. The pore diameter is also important because for smaller pores the adsorption of larger molecules would present difficulties of access to the internal pores of the solid.

The number of basic sites on the surface of the samples was obtained by the integration of desorption peaks of TPD-CO $\mathrm{CO}_{2}$. The strength of the sites can be determined by the temperature at which the desorption peak occurs. Note that samples reveal maximum desorption temperatures (Tmax) above $280{ }^{\circ} \mathrm{C}$, which corresponds to medium $\left(240-303{ }^{\circ} \mathrm{C}\right)$ and strong $\left(326-396^{\circ} \mathrm{C}\right)$ sites (Pavel et al. 2012) $)^{\mathrm{Fe} \text {, }}$ $\mathrm{Co}, \mathrm{Ni}, \mathrm{Cu}$ and $\mathrm{Zn}$

Table I shows the HC-Mg sample exhibited the highest total number of basic sites. When $\mathrm{Al}$ or $\mathrm{Fe}$ was added to $\mathrm{Mg}$, there was a decrease in total sites for both samples (Carvalho et al. 2012). However, Tmax increased with the addition of the trivalent cation in the $\mathrm{Mg}$ structure, that is, the HDL-MgAl and HDL-MgFe samples showed an increase in the strength of basic sites.

Based on desorption temperatures in TPD, the comparison between the hydrotalcites showed that HDL-MgFe provides strong basic sites than HDL$\mathrm{MgAl}$. However, samples containing Fe exhibit lower total number of basic sites than samples with Al.

Also, it is important to highlight that the effect of $\mathrm{pH}$ is significant in the adsorption stud, although the intensity of the RR120 solution color was affected by sudden changes in $\mathrm{pH}$. The consideration of the alkaline properties through $\mathrm{pH}$ PZC is an important parameter for the solid adsorption capacity. The $\mathrm{pH}$ PzC value is 11 for HDL-MgAl and $\mathrm{HCMg}$, and 8 for HDL-MgFe solid. In this case, as RR120 is an acid dye, the hydroxyl group on the adsorbents surface can interact with the dye protons, providing a favorable electrostatic interaction in the removal process.

\section{Effect of the adsorbent dosage}

Adsorption experiments of RR120 dye in aqueous phase were performed at different adsorbent dosages. Figure 3 shows the effect of the adsorbent dosage on the removal of RR120 using the HDL-MgAl, HDL$\mathrm{MgFe}$ and $\mathrm{HCMg}$ solids.

Figure 3 shows the concentration of the adsorbed dye increases with the increasing adsorbent dosage. Removal depends on the initial concentration of dye, which was approximately $30 \mathrm{mg} / \mathrm{L}$. It may be evident in figure 3 that after $1 \mathrm{~g} / \mathrm{L}$ for HDL$\mathrm{MgAl}$ and $\mathrm{HC}-\mathrm{Mg}$, and after $2 \mathrm{~g} / \mathrm{L}$ of HDL-MgFe,

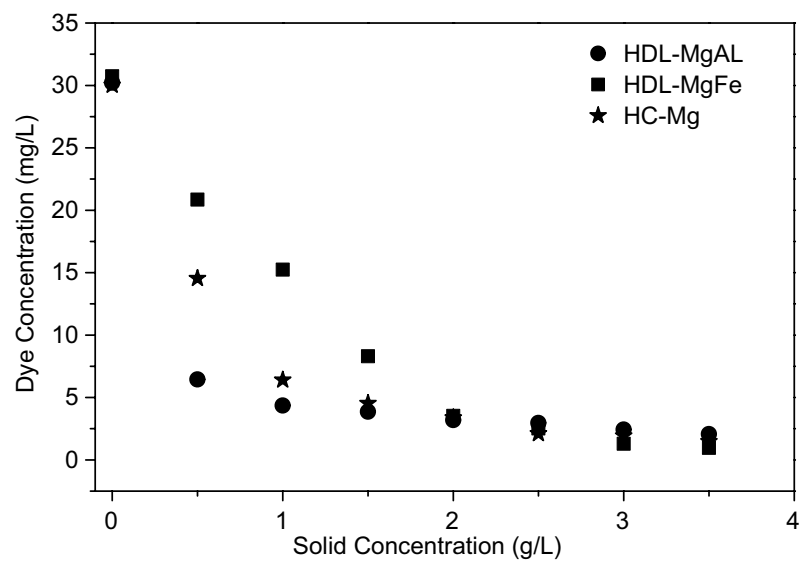

Fig. 3. Effect of the adsorbent dosage in the removal of the Reactive Red 120 dye. Conditions: adsorption time: $30 \mathrm{~min}$, initial concentration: $30 \mathrm{mg} / \mathrm{L}$ of the dye. HDL$\mathrm{MgAl}$ : hydrotalcite of Mg-Al, HDL-MgFe: hydrotalcite of $\mathrm{Mg}-\mathrm{Fe}, \mathrm{HC}-\mathrm{Mg}$ : hydroxycarbonate of $\mathrm{Mg}$

equilibrium was attained, which indicates the saturation of the solid surface. However, at a low adsorbent dose $(0.5 \mathrm{~g} / \mathrm{L}), \mathrm{HDL}-\mathrm{MgAl}$ provided a greater removal of dye $(78.8 \%)$. The maximum adsorbent value was obtained by HDL-MgFe, with a removal percentage of $96.9 \%$. This fact may be related to the larger surface area of the HDL-MgFe hydrotalcite, which results in greater total dye removal capacity.

The maximum removal was reached at adsorbent dose of $3.5 \mathrm{~g} / \mathrm{L}$ with removal values of 93,96 , and $95 \%$ for HDL-MgAl, HDL-MgFe and $\mathrm{HC}-\mathrm{Mg}$, respectively. Therefore, in terms of costs and considering the equilibrium evidenced in figure 3 , it is clear that with an adsorbent dose of $2.5 \mathrm{~g} / \mathrm{L}$ for HDL-MgAl and HC-Mg, and $2 \mathrm{~g} / \mathrm{L}$ for HDL-MgFe, a dye removal near $90 \%$ was reached. These values are very close to the maximum removal achieved in the tests.

\section{Effect of the time of adsorption}

Figure 4 shows the removal of RR120 dye at different adsorption times. The adsorbent dosage for solids was $2.5 \mathrm{~g} / \mathrm{L}$ for HDL-MgAl and $\mathrm{HCMg}$, and $2.0 \mathrm{~g} / \mathrm{L}$ for HDL-MgFe.

The evaluated solids show very fast kinetics for the process, since after $5 \mathrm{~min}$ more than $60 \%$ of the dye was adsorbed with HDL-MgFe, and above $80 \%$ with HDL-MgAl and HC-Mg. This result is important, since a rapid removal of adsorbate and achieving equilibrium in a short time indicate that the adsorbents used are efficient. The lowest percentage removed with $\mathrm{HDL}-\mathrm{MgFe}$ in this time interval may be related to the lower dose of adsorbent used. 


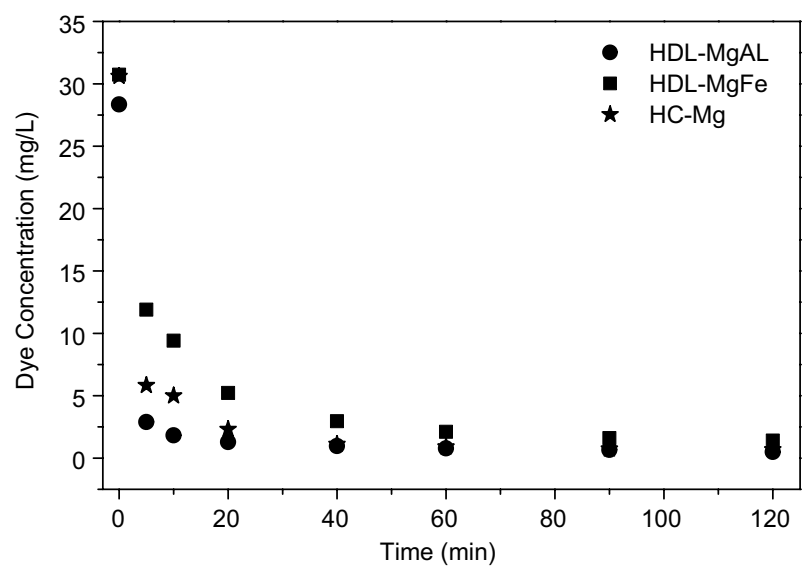

Fig 4. Effect of adsorption time in the removal of the Reactive Red 120 dye. Conditions: initial concentration of about $30 \mathrm{~g} / \mathrm{L}$ of dye, solids dosage of $2.5 \mathrm{~g} / \mathrm{L}$ for HDL-MgAl and $\mathrm{HC}-\mathrm{Mg}$, and $2.0 \mathrm{~g} / \mathrm{L}$ for HDL-MgFe. HDL-MgAl: hydrotalcite of $\mathrm{Mg}-\mathrm{Al}$, HDL-MgFe: hydrotalcite of $\mathrm{Mg}$ $\mathrm{Fe}, \mathrm{HC}-\mathrm{Mg}$ : hydroxycarbonate of $\mathrm{Mg}$

It can also be observed that for the three solids tested, the kinetics of dye removal is faster during the first $20 \mathrm{~min}$, but after a period of $60 \mathrm{~min}$ dye removal occurs slowly and the variation of concentrations is not relevant over time. This happens because initially all the active sites are free at the surface of the adsorbent solids, which results in a fast adsorption. When occupied by the sorbate, free sites decrease, leading to saturation of the solids. Therefore, it was determined that the most suitable time for the removal of RR 120 is $60 \mathrm{~min}$ for the three solids studied.

\section{Adsorption kinetics}

Knowing the effect of contact time on the RR120 adsorption experiments made it possible to study the kinetics of the process. The pseudo-first-order model (Lagergren 1898) describes the adsorption rate based on the adsorption capacity. It is expressed by the following equation:

$q_{t}=q_{1}\left(1-\exp \left(-k_{1} t\right)\right.$

The pseudo-second-order equation is expressed as follows (Ho and McKay 1999):

$q_{e}=q m k_{L} \frac{C_{e}}{1+k_{L} C_{e}}$

The calculated parameters of the kinetic models are shown in table II, where it can be seen that the values obtained for RR120 adsorption were 27.07, 14.08, and $34.07 \mathrm{mg} / \mathrm{g}$ for HDL-MgAl, HDL-MgFe, and $\mathrm{HC}-\mathrm{Mg}$, respectively. The kinetics of dye adsorption followed the pseudo-second-order model because its determination coefficients were higher $\left(\mathrm{R}^{2}=0.9954\right.$, 0.9966, and 0.9979 for HDL-MgAl, HDL-MgFe and $\mathrm{HC}-\mathrm{Mg}$, respectively). This model suggests that chemisorption is a rate limiting step of adsorption. Electrostatic attraction, anion exchange and chemical bonding may be involved in the dye adsorption process (Shan et al. 2015). The same model was found for the adsorption of RR120 in other studies (Tabak et al. 2010, Demarchi et al. 2013, Shan et al. 2015).

\section{Adsorption isotherms}

TABLE II. CALCULATED PARAMETERS OF THE PSEUDO FIRST-ORDER AND PSEUDO SECONDORDER KINETIC MODELS FOR ADSORPTION OF REACTIVE RED 120 OVER HDL-MgAl, HDL-MgFe, AND HC-Mg

\begin{tabular}{lll}
\hline $\begin{array}{l}\text { Adsorbent } \\
\text { solid }\end{array}$ & $\begin{array}{l}\text { Pseudo-first order } \\
\text { model }\end{array}$ & $\begin{array}{l}\text { Pseudo-second } \\
\text { order model }\end{array}$ \\
\hline $\begin{array}{l}\mathrm{HDL}-\mathrm{MgAl} \\
q_{\text {exp }}=\end{array}$ & $\mathrm{q}_{1}(\mathrm{mg} / \mathrm{g})=27.07$ & $\mathrm{q}_{2}(\mathrm{mg} / \mathrm{g})=27.10$ \\
$27.84 \mathrm{mg} / \mathrm{g}$ & $\mathrm{k}_{1}\left(\mathrm{~min}^{-1}\right)=2.21$ & $\mathrm{k}_{2}\left(\mathrm{~min}^{-1}\right)=45566.38$ \\
\hline $\mathrm{HDL}-\mathrm{MgFe}$ & $\mathrm{q}_{1}(\mathrm{mg} / \mathrm{g})=14.08$ & $\mathrm{R}^{2}=0.995$ \\
$\mathrm{q}_{2}(\mathrm{mg} / \mathrm{g})=15.00$ \\
$14.66 \mathrm{mg} / \mathrm{g}$ & $\mathrm{k}_{1}\left(\mathrm{~min}^{-1}\right)=0.18$ & $\mathrm{k}_{2}\left(\mathrm{~min}^{-1}\right)=980.00$ \\
\hline $\mathrm{HC}-\mathrm{Mg}$ & $\mathrm{q}_{1}\left(\mathrm{mg}^{2} \mathrm{~g}\right)=34.07$ & $\mathrm{R}^{2}=0.99$ \\
$\mathrm{q}_{\text {exp }}=$ & $\mathrm{k}_{1}\left(\mathrm{~min}^{-1}\right)=0.38$ & $\mathrm{k}_{2}\left(\mathrm{~min}^{-1}\right)=41792.03$ \\
$34.92 \mathrm{mg} / \mathrm{g}$ & $\mathrm{R}^{2}=0,9894$ & $\mathrm{R}^{2}=0,9979$ \\
\hline
\end{tabular}

* $q_{\text {exp }}$ is the experimental capacity of adsorption, $q_{1}$ and $q_{2}$ are the pseudo-first rate and pseudo-second order constants, respectively, $q_{\text {exp }}$ is the amount of solute adsorbed at equilibrium, and $k_{1}$ and $k_{2}$ are the velocity constants

HDL-MgAl: hydrotalcite of Mg-Al, HDL-MgFe: hydrotalcite of $\mathrm{Mg}-\mathrm{Fe}, \mathrm{HC}-\mathrm{Mg}$ : hydroxycarbonate of $\mathrm{Mg}$

In order to establish the most appropriate correlation for the equilibrium curves and to estimate the parameters for an adsorption system it is important to establish the most appropriate correlation for the equilibrium curves. The adsorption capacity at equilibrium can be obtained by measuring the adsorption isotherm of the adsorbent (Cheung et al. 2009).

Therefore, to establish the most appropriate correlation for the equilibrium curves and to estimate the parameters of the isotherms, the Langmuir equation (4) (Langmuir 1918), the Freundlich equation (5) (Freundlich 1906), and the Redlich-Peterson equation (6) (Wu et al. 2010) were used.

$q_{e}=K_{F} C_{e}^{1 / n}$ 
$q_{e}=\frac{K_{R} C_{e}}{1+a R C_{e}^{N}}$

where $q e(\mathrm{mg} / \mathrm{g})$ is the equilibrium adsorption amount at equilibrium concentration of $\mathrm{Ce}(\mathrm{mg} / \mathrm{L}) ; q m$ is the maximum capacity of the adsorbent $(\mathrm{mg} / \mathrm{g}) ; K_{\mathrm{L}}$ is the Langmuir adsorption constant $(\mathrm{L} / \mathrm{mg}) ; K_{\mathrm{F}}\left(\mathrm{mg}^{1-\mathrm{n}} / \mathrm{Ln} /\right.$ $\mathrm{g}^{-1}$ ) and $n$ are the Freundlich affinity coefficient and linearity, respectively; $K_{\mathrm{R}}$ is the Redlich-Peterson adsorption constant $(\mathrm{L} / \mathrm{mg}), a R$ is a Redlich-Peterson isotherm constant $(\mathrm{L} / \mathrm{mg})$, and $N$ is a Redlich-Peterson isotherm exponent.

In order to predict whether the adsorption of RR120 in aqueous solution was efficient or not, the shape of the isotherm, the statistical parameters and the values of the constants for each non-linearized model were taken into consideration.

Figure 5 shows the experimental adsorption isotherms for the removal of RR120 using HC-Mg as adsorbent and compares them with the Langmuir, Freundlich and Redlich-Peterson models.

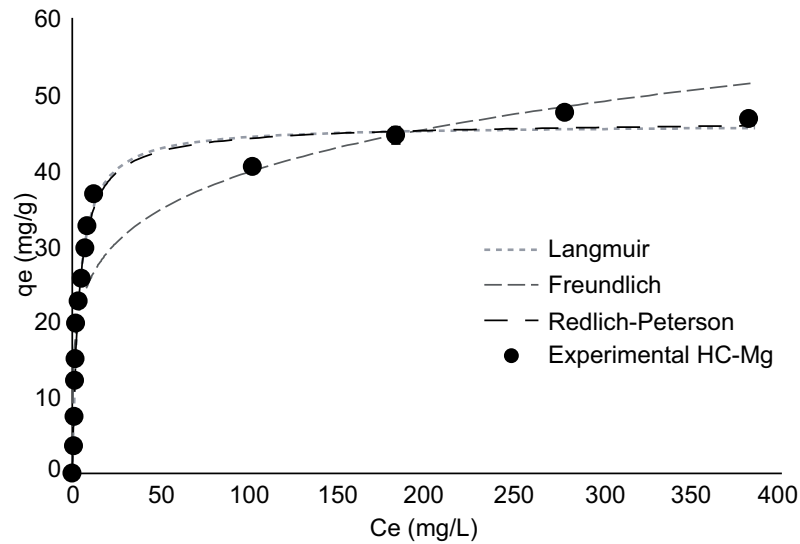

Fig. 5. Comparison between the values predicted by the Langmuir, Freundlich and Redlich-Peterson models and the adsorption experimental isotherm of Reactive Red 120 in hydroxycarbonate of $\mathrm{Mg}(\mathrm{HC}-\mathrm{Mg})$. Conditions: adsorption time: $60 \mathrm{~min}$; adsorbent dose: $2.5 \mathrm{~g} / \mathrm{L}$

Table III shows that the Langmuir and RedlichPeterson models best described the adsorption equilibrium data of RR120 because they presented $R^{2}$ values close to 1 .

Figure 6 shows the experimental adsorption isotherms compared with the Langmuir, Freundlich and Redlich-Peterson models for the removal of RR120 using HDL-MgAl.

Table IV reports the isotherm parameters evaluated for HDL-MgAl in the removal of RR120. As it can be seen, the Langmuir and Redlich-Peterson
TABLE III. PARAMETERS OF THE LANGMUIR, FREUNDLICH AND REDLICH-PETERSON MODELS FOR HC-Mg

\begin{tabular}{lll}
\hline Freundlich & Langmuir & Redlich-Peterson \\
\hline$k_{\mathrm{F}}=.16 .48$ & $q_{\max }=45.94$ & $q_{\mathrm{m}}=43.88$ \\
$n=5.23$ & $k_{\mathrm{L}}=0.27$ & $k_{\mathrm{R}}=0.29$ \\
& & $n=0.99$ \\
$\mathrm{R}^{2}=0.87$ & $\mathrm{R}^{2=} 0.98$ & $\mathrm{R}^{2}=0.98$ \\
Error $=1.27$ & Error $=0.15$ & Error $=0.15$ \\
\hline
\end{tabular}

$*^{*} k_{\mathrm{F}}, k_{\mathrm{L}}$ and $k_{\mathrm{R}}$ are Freundlich, Langmuir and Redlich-Peterson constants, respectively; $n$ is an isotherm exponent; $q_{\mathrm{m}}$ and $q_{\max }$ are the maxima capacities of the adsorbent $(\mathrm{mg} / \mathrm{g})$

$\mathrm{HC}-\mathrm{Mg}$ : hydroxycarbonate of $\mathrm{Mg}$

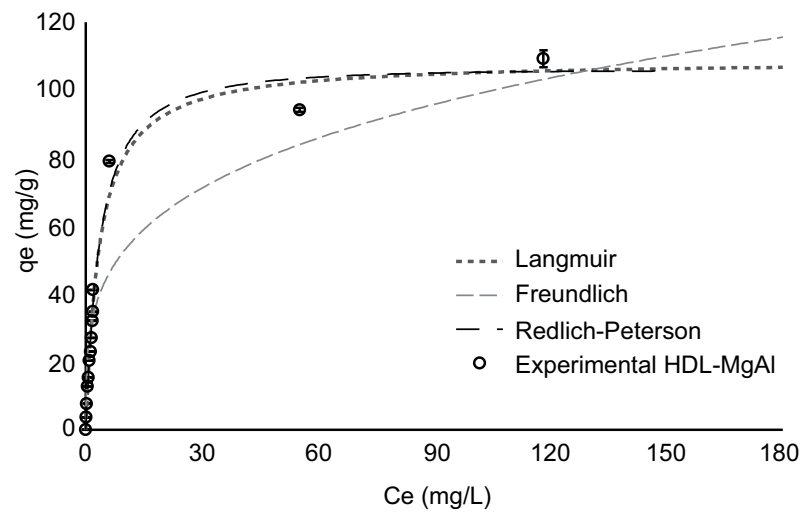

Fig. 6. Comparison between the values predicted by the Langmuir isotherms, the Freundlich and Redlich-Peterson models, and experimental adsorption isotherms of Reactive Red 120, in hydrotalcite of MgAl (HDL-MgAl). Conditions: adsorption time: $60 \mathrm{~min}$; adsorbent dose: $2.5 \mathrm{~g} / \mathrm{L}$

TABLE IV. PARAMETERS OF THE LANGMUIR, FREUNDLICH AND REDLICH-PETERSON MODELS FOR HC-Mg-Al

\begin{tabular}{lll}
\hline Freundlich & Langmuir & Redlich-Peterson \\
\hline$k_{\mathrm{F}}=28.38$ & $q_{\max }=108.83$ & $q_{\mathrm{m}}=120.04$ \\
$n=3.69$ & $k_{\mathrm{L}}=0.28$ & $k_{\mathrm{R}}=0.24$ \\
- & - & $n=1.021$ \\
$\mathrm{R}^{2}=0.91$ & $\mathrm{R}^{2}=0.98$ & $\mathrm{R}^{2}=0.98$ \\
Error $=3.47$ & Error $=0.47$ & Error $=0.45$ \\
\hline
\end{tabular}

$*_{\mathrm{F}_{\mathrm{F}}} k_{\mathrm{L}}$ and $k_{\mathrm{R}}$ are Freundlich, Langmuir and Redlich-Peterson constants, respectively; $n$ is an isotherm exponent; $q_{\mathrm{m}}$ and $q_{\max }$ are the maxima capacities of the adsorbent $(\mathrm{mg} / \mathrm{g})$

$\mathrm{HC}-\mathrm{Mg}-\mathrm{Al}$ : hydrotalcite OF Mg-Al

models best described the adsorption equilibrium data for the removal of RR120 with this solid, since an $\mathrm{R}^{2}$ value close to 1 and low errors were obtained. 
Similarly, figure 7 shows the experimental adsorption isotherms for the removal of RR120 and compares them with the Langmuir, Freundlich and Redlich-Peterson models in the case of HDL-MgFe.

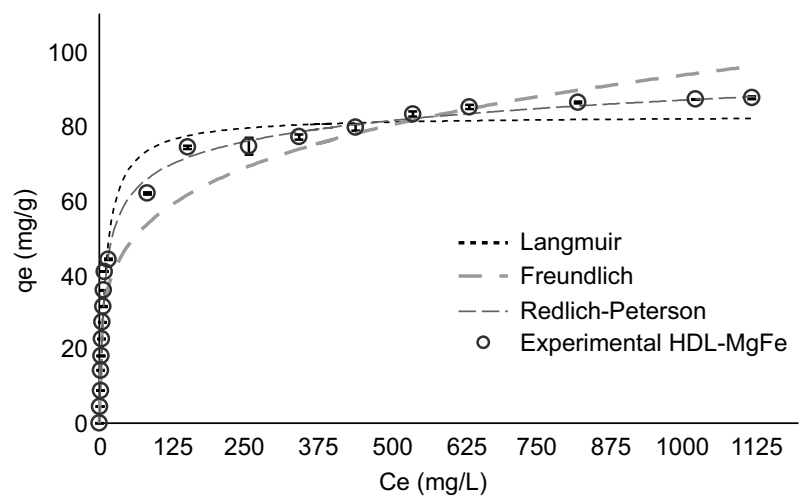

Fig. 7. Comparison between values predicted by the Langmuir, Freundlich and Redlich-Paterson models and the experimental data isotherm of Reactive Red 120 adsorption in the hydrotalcite of $\mathrm{MgFe}$ (HDL-MgFe). Conditions: adsorption time: $60 \mathrm{~min}$; adsorbent dose: $2 \mathrm{~g} / \mathrm{L}$

Table $\mathbf{V}$ shows that the Redlich-Peterson model best described the equilibrium data of the RR120 with HDL-MgFe, with an $\mathrm{R}^{2}$ value close to 1 and a minor error.

TABLE V. PARAMETERS OF THE LANGMUIR, FREUNDLICH AND REDLICH-PETERSON MODELS FOR HC-MgFe

\begin{tabular}{lll}
\hline Freundlich & Langmuir & Redlich-Peterson \\
\hline$k_{\mathrm{F}}=20.02$ & $q_{\max }=82.59$ & $q_{\mathrm{m}}=48.87$ \\
$n=4.48$ & $k_{\mathrm{L}}=0.09$ & $k_{\mathrm{R}}=0.22$ \\
& & $N=0.92$ \\
$\mathrm{R}^{2}=0.94$ & $\mathrm{R}^{2}=0.98$ & $\mathrm{R}^{2}=0.99$ \\
Error $=1.04$ & Error $=0.34$ & Error $=0.11$ \\
\hline
\end{tabular}

$*_{k_{\mathrm{F}}}, k_{\mathrm{L}}$ and $k_{\mathrm{R}}$ are Freundlich, Langmuir and Redlich-Peterson constants, respectively; $n$ is an isotherm exponent, $q_{\mathrm{m}}$ and $q_{\max }$ are the maxima capacities of the adsorbent $(\mathrm{mg} / \mathrm{g})$

$\mathrm{HC}-\mathrm{MgFe}$ : hydrotalcite of $\mathrm{Mg}-\mathrm{Fe}$

Figures 5, 6 and 7 show the adsorption isotherm models considered for the three solids used in the removal of RR120. The models that have a better correlation with the experimental data are Langmuir and RedlichPeterson, since they adjust the experimental results in a satisfactory way unlike the other models studied, which do not adjust to the data neither describe the thermodynamic behavior of the adsorption process.

It can be noticed that the adsorption capacity increases with the equilibrium concentration of the dye in the solution due to the progressive saturation of the monolayer for the studied solids. The Langmuir and Redlich-Peterson models were present in the three systems, although there was not a significant difference between them. These models indicate that the processes occurred at homogeneous and specific sites.

The results of tables III, IV and $\mathbf{V}$ show the higher $q_{\max }$ values for HDL-MgAl, although it is not the solid with the highest surface area. This fact can be explained by the greater number and strength of basic sites of that favors the adsorption of dye with acidic characteristics. Although $\mathrm{HC}-\mathrm{Mg}$ has the highest number of basic sites, these present lower basic strength, as is observed in table I. On the other hand, although the basic sites of HDL-MgFe showed higher strength, it has a lower number of sites than HDL$\mathrm{MgAl}$, indicating a compromise between strength and number of sites. The maximum adsorption capacity is not only the surface influence of the adsorbent solids but also involves the dye chemistry and the acidbase properties of the solids. It should be noted that the experimental conditions used in the adsorption process influence the performance of the adsorbent. In addition, the retention of the dyes by the materials involves several attractive forces, such as ionic interactions, Van de Waals forces, hydrogen bonds and covalent bonds. Depending on the type of the dye, one or more forces act in the adsorption process.

The results of the models were compared with those obtained by other authors using the same dye and different sorbent solids. As can be seen in table VI, the models obtained correspond to the Langmuir and Redlich-Peterson models, as well as the present study.

As can be seen in the table VI, all models evaluated for the removal of RR120 with different sorbent solids describe a Langmuir equilibrium, where the results obtained by the present study for HDLMgAl $\left(q_{\mathrm{m}}\right.$ and $\mathrm{q}_{\max }$ values of 120.04 and $108.83 \mathrm{mg} / \mathrm{g}$, respectively) are much higher than the rest of the values compared in the same table. The value obtained in the present work is lower than the results obtained by Demarchi et al. (2013) (433 mg/g), but the solid used by these authors had highly different characteristics. However, the values of $q_{\mathrm{m}}$ and $q_{\mathrm{max}}$ obtained in the present work were superior to those reported by Shan et al. (2015) with HDL-MgAlCO 3 , which has similar properties to the HDL-MgAl used here, showing 
TABLE VI. COMPARISON OF THE ISOTHERMS MODELS OF THE STUDIED MATERIALS WITH OTHER SOLID ADSORBENTS

\begin{tabular}{llll}
\hline $\begin{array}{l}\text { Solid } \\
\text { adsorbents }\end{array}$ & $\begin{array}{l}\text { Isotherm } \\
\text { model }\end{array}$ & $\begin{array}{l}\text { Maximum capacity of } \\
\text { the adsorbent (mg/g) }\end{array}$ & Reference \\
\hline $\begin{array}{l}\text { Hydrotalcite } \\
\text { of MgAl }\end{array}$ & $\begin{array}{l}\text { Langmuir } \\
\text { Redlich-Peterson }\end{array}$ & $\begin{array}{l}q_{\mathrm{max}}=108.8 \\
q_{\mathrm{m}}=120.0\end{array}$ & This study \\
\hline $\begin{array}{l}\text { Hydrotalcite } \\
\text { of MgFe }\end{array}$ & Langmuir & $q_{\max }=82.6$ & This study \\
\hline $\begin{array}{l}\text { Hydroxycarbonate } \\
\text { of Mg }\end{array}$ & Redlich-Peterson & $q_{\mathrm{m}}=48.9$ & This study \\
\hline $\begin{array}{l}\text { Hydrotalcite of } \\
\text { MgAlCO } 3\end{array}$ & $\begin{array}{l}\text { Langmuir } \\
\text { Redlich-Peterson }\end{array}$ & $\begin{array}{l}q_{\mathrm{max}}=45.9 \\
q_{\mathrm{m}}=43.9\end{array}$ & (Shan et al. 2015) \\
\hline $\begin{array}{l}\text { cetylpyridinium-bentonite } \\
\text { chitosan-Fe(III)-crosslinked }\end{array}$ & Langmuir & 59.5 & (Tabak et al. 2010) \\
\hline $\begin{array}{l}\text { Lhitosan/modified } \\
\text { montmorillonite }\end{array}$ & Langmuir-Freundlich & 433.8 & (Demarchi et al. 2013) \\
\hline
\end{tabular}

that the basic solids tested in this study are a good alternative for the removal acid dyes such as RR120.

\section{CONCLUSIONS}

The results of the XRD analysis show that the obtained solids have high crystallinity with hydrotalcitetype structure for HDL-MgAl and HDL-MgFe, and hydroxicarbonate-type structure for $\mathrm{HC}-\mathrm{Mg}$.

The effect of the trivalent ion on the properties of the magnesium-based hydrotalcites was significant, since iron favors the formation of a solid with a greater specific area (HDL-MgFe), whereas aluminum favors the formation of a solid with basic properties (HDL-MgAl). Alkaline characteristics reveal to be more important than the specific surface area of these hydrotalcites for the removal of RR120.

A removal of about $90 \%$ for the RR120 dye was achieved with adsorbent dosages of $2.5 \mathrm{~g} / \mathrm{L}$ of $\mathrm{HDLMgAl}$ and $\mathrm{HC}-\mathrm{Mg}$, and $2 \mathrm{~g} / \mathrm{L}$ of HDL-MgFe. Runs conducted at different adsorption times showed that the most suitable condition for the removal of RR120 is a time of $60 \mathrm{~min}$ for the three adsorbent solids.

The adsorption kinetics described for the pseudosecond order model and the isotherms showed that the Langmuir and Redlich-Peterson models better explained the equilibrium data of the RR120 dye with the HDL-MgAl, HDL-MgFe and HC-Mg solids.

\section{ACKNOWLEDGMENTS}

The authors thank to the Higher Education Personnel Improvement Coordination (CAPES), for the financial support for this work.

\section{REFERENCES}

Absalan G., Asadi M., Kamran S., Sheikhian L. and Goltz D.M. (2011). Removal of reactive red-120 and 4-(2-pyridylazo) resorcinol from aqueous samples by $\mathrm{Fe}_{3} \mathrm{O}_{4}$ magnetic nanoparticles using ionic liquid as modifier. J. Hazard. Mater. 192 (2), 476-484.

DOI: 10.1016/j.jhazmat.2011.05.046

Beall G., Duraia E., El-Tantawy F., Al-Hazmi F., AlGhamdi A. (2013). Rapid fabrication of nanostructured magnesium hydroxide and hydromagnesite via microwave-assisted technique. Powder Technol. 234, 26-31.

DOI: 10.1016/j.powtec.2012.09.029

Bharali D. and Deka R.C. (2017). Preferential adsorption of various anionic and cationic dyes from aqueous solution over ternary $\mathrm{CuMgAl}$ layered double hydroxide. Colloid. Surface. A 525, 64-76.

DOI: $10.1016 /$ j.colsurfa.2017.04.060

Carvalho D.L., de Avillez R.R., Rodrigues M.T., Borges L.E.P. and Appel L.G. (2012). Mg and Al mixed oxides and the synthesis of n-butanol from ethanol. Appl. Catal. A-Gen. 415-416, 96-100.

DOI: 10.1016/j.apcata.2011.12.009 
Cavani F., Trifirò F. and Vaccari A. (1991). Hydrotalcitetype anionic clays: Preparation, properties and applications. Catal. Today 11 (2), 173-301.

DOI: 10.1016/0920-5861(91)80068-K

Çelekli A., Yavuzatmaca M. and Bozkurt H. (2009). Kinetic and equilibrium studies on the adsorption of reactive red 120 from aqueous solution on Spirogyra majuscula. Chem. Eng. J. 152 (1), 139-45.

DOI: $10.1016 /$ j.cej.2009.04.016

Cheung W.H., Szeto Y.S. and McKay G. (2009). Enhancing the adsorption capacities of acid dyes by chitosan nano particles. Bioresource. Technol. 100 (3), 11431148. DOI: 10.1016/j.biortech.2008.07.071

Cho I.H. and Zoh K.D. (2007). Photocatalytic degradation of azo dye (Reactive Red 120) in $\mathrm{TiO}_{2} / \mathrm{UV}$ system: Optimization and modeling using a response surface methodology (RSM) based on the central composite design. Dyes Pigments 75, 533-543.

DOI: 10.1016/j.dyepig.2006.06.041

Crini G. (2006). Non-conventional low-cost adsorbents for dye removal: A review. Bioresource. Technol. 97 (9), 1061-1085. DOI: 10.1016/j.biortech.2005.05.001

Demarchi C.A., Campos M. and Rodrigues C.A. (2013). Adsorption of textile dye Reactive Red 120 by the chitosan-Fe(III)- crosslinked: Batch and fixed-bed studies. J. Environ. Chem. Eng. 1 (4), 1350-1358. DOI: $10.1016 /$ j.jece.2013.10.005

Fan G., Li F, Evans D.G. and Duan X. (2014). Catalytic applications of layered double hydroxides: Recent advances and perspectives. Chem. Soc. Rev. 43 (20), 7040-7066. DOI: 10.1039/c4cs00160e

Franco A.E., Bonfante C., Marques M., de Pelegrini R. and Feris L.A. (2017). Removal of amoxicillin from water by adsorption onto activated carbon in batch process and fixed bed column: Kinetics, isotherms, exprimental design and breakthrough curves modelling. J. Clean. Prod. 161 (10), 947-956.

DOI: 10.1016/j.jclepro.2017.05.197

Freundlich H.M. (1906). Over the adsorption in solution. J. Phys. Chem. A. 57, 385-470

Guo Y., Zhu Z., Qiu Y. and Zhao J. (2013). Enhanced adsorption of acid brown 14 dye on calcined $\mathrm{Mg} / \mathrm{Fe}$ layered double hydroxide with memory effect. Chem. Eng. J. 219, 69-77. DOI: 10.1016/j.cej.2012.12.084

Haro N.K., Del Vecchio P., Marcilio N.R. and Féris L.A. (2017). Removal of atenolol by adsorption - Study of kinetics and equilibrium. J. Clean. Prod. 154, 214-219. DOI: 10.1016/j.jclepro.2017.03.217

Ho Y.S. and McKay G. (1999). Pseudo-second order model for sorption processes. Process Biochem. 34 (5), 451465. DOI: 10.1016/S0032-9592(98)00112-5

Huang Z., Li Y., Chen W., Shi J., Zhang N., Wang X., Li Z., Gao L. and Zhang Y. (2017). Modified bentonite adsorption of organic pollutants of dye wastewater. Mater. Chem. Phys. 202, 266-276.

DOI: 10.1016/j.matchemphys.2017.09.028

Kittinaovarat S., Kansomwan P. and Jiratumnukul N. (2010). Chitosan/modified montmorillonite beads and adsorption Reactive Red 120. Appl. Clay. Sci. 48 (1-2), 87-91. DOI: 10.1016/j.clay.2009.12.017

Kooh M.R.R., Dahri M.K. and Lim L.B.L. (2017a). Removal of methyl violet $2 \mathrm{~B}$ dye from aqueous solution using Nepenthes rafflesiana pitcher and leaves. Applied Water Science 7 (7), 3859-3868.

DOI: $10.1007 / \mathrm{s} 13201-017-0537-1$

Kooh M.R.R., Dahri M.K. and Lim L.B.L. (2017b). Removal of the methyl violet $2 \mathrm{~B}$ dye from aqueous solution using sustainable adsorbent Artocarpus odoratissimus stem axis. Applied Water Science 7 (7), 3573-3581. DOI: 10.1007/s13201-016-0496-y

Kusvuran E., Gulnaz O., Irmak S., Atanur O.M., Yavuz H.I. and Erbatur O. (2004). Comparison of several advanced oxidation processes for the decolorization of Reactive Red 120 azo dye in aqueous solution. J. Hazar. Mater. 109 (1-3), 85-93.

DOI: 10.1016/j.jhazmat.2004.03.009

Lagergren S. (1898). Zur theorie der sogenannten adsorption gel`ster stoffe, Kungliga Svenska Vetenskapsakademiens. Handlingar 24 (4), 1-39.

Langmuir I. (1918). The adsorption of gases on plane surfaces of glass, mica and platinum. J. Am. Chem. Soc. 40 (9), 1361-1403. DOI: 10.1021/ja02242a004

Lazaridis N., Karapantsios T. D. and Georgantas D. (2003). Kinetic analysis for the removal of a reactive dye from aqueous solution onto hydrotalcite by adsorption. Water Res. 37 (12), 3023-3033. DOI: 10.1016/S0043-1354(03)00121-0

Lemlikchi W., Drouiche N., Belaicha N., Oubagha N., Baaziz B. and Mecherri M.O. (2015). Kinetic study of the adsorption of textile dyes on synthetic hydroxyapatite in aqueous solution. J. Ind. Eng. Chem. 32, 233-237. DOI: 10.1016/j.jiec.2015.08.023

Paul J., Rawat K.P., Sarma K.S.S. and Sabharwal S. (2011). Decoloration and degradation of Reactive Red-120 dye by electron beam irradiation in aqueous solution. Appl. Radiat. Isotopes 69 (7), 982-987. DOI: 10.1016/j.apradiso.2011.03.009

Pavel O.D., Tichit D. and Marcu I.C. (2012). Acido-basic and catalytic properties of transition-metal containing $\mathrm{Mg}-\mathrm{Al}$ hydrotalcites and their corresponding mixed oxides. Appl. Clay Sci. 61, 52-58. DOI: 10.1016/j.clay.2012.03.006

Perez-Lopez O.W., Senger A., Marcilio N.R. and Lansarin M.A. (2006). Effect of composition and thermal pretreatment on properties of $\mathrm{Ni}-\mathrm{Mg}-\mathrm{Al}$ catalysts for $\mathrm{CO}_{2}$ reforming of methane. Appl. Catal. A-Gen. 
303 (2), 234-244. DOI: 10.1016/j.apcata.2006.02.024

Punjongharn P., Meevasana K. and Pavasant P. (2008). Influence of particle size and salinity on adsorption of basic dyes by agricultural waste: Dried seagrape (Caulerpa lentillifera). J. Environ. Sci. 20 (6), 760-768. DOI: 10.1016/S1001-0742(08)62124-5

Rives V., del Arco M. and Martín C. (2013). Layered double hydroxides as drug carriers and for controlled release of non-steroidal anti-inflammatory drugs (NSAIDs): A review. J. Control. Release 169 (1-2), 28-39. DOI: 10.1016/j.jconrel.2013.03.034

Senthilkumaar S., Kalaamani P., Porkodi K., Varadarajan P.R. and Subburaam C.V. (2006). Adsorption of dissolved reactive red dye from aqueous phase onto activated carbon prepared from agricultural waste. Bioresource. Technol. 97 (14), 1618-1625.

DOI: 10.1016/j.biortech.2005.08.001

Shan R., Yan L., Yang Y., Yang K., Yu S., Yu H., Zhu B. and $\mathrm{Du}$ B. (2015). Highly efficient removal of three red dyes by adsorption onto $\mathrm{Mg}-\mathrm{Al}$-layered double hydroxide. J. Ind. Eng. Chem. 21, 561-568.

DOI: 10.1016/j.jiec.2014.03.019

Tabak A., Baltas N., Afsin B., Emirik M., Caglar B. and Eren E. (2010). Adsorption of Reactive Red 120 from aqueous solutions by cetylpyridinium-bentonite. J. Chem. Technol. Biot. 85 (9), 1199-1207.
DOI: $10.1002 /$ jctb. 2416

Tsyganok A. and Sayari A. (2006). Incorporation of transition metals into $\mathrm{Mg}$ - $\mathrm{Al}$ layered double hydroxides: Coprecipitation of cations vs. their pre-complexation with an anionic chelator. J. Solid State Chem. 179 (6), 1830-1841. DOI: 10.1016/j.jssc.2006.03.029

Uddin M.T., Islam M.A., Mahmud S. and Rukanuzzaman M. (2009). Adsorptive removal of methylene blue by tea waste. J. Hazard. Maters. 164 (1), 53-60.

DOI: 10.1016/j.jhazmat.2008.07.131

Vaccari A. (1998). Preparation and catalytic properties of cationic and anionic clays. Catal. Today 41 (1-3), 5371. DOI: 10.1016/S0920-5861(98)00038-8

Vicente R. (2002). Characterisation of layered double hydroxides and their decomposition products. Mater. Chem. Phys. 75 (1-3), 19-25. DOI: 10.1016/s0254-0584(02)00024-x

Wu F.C., Liu B.L., Wu K.T. and Tseng R.L. (2010). A new linear form analysis of Redlich-Peterson isotherm equation for the adsorptions of dyes. Chem. Eng. J. 162 (1), 21-27. DOI: 10.1016/j.cej.2010.03.006

Zubair M., Daud M., McKay G., Shehzad F. and al-Harthi M.A. (2017). Recent progress in layered double hydroxides (LDH)-containing hybrids as adsorbents for water remediation. Appl. Clay Sci. 143, 279-292.

DOI: 10.1016/j.clay.2017.04.002 